\title{
Períodos de Interferência das Plantas Daninhas na Cultura da Soja nos Sistemas de Semeadura Direta e Convencional ${ }^{1}$
}

\author{
Periods of Weed Interference in Soybean Under Tillage and No-Tillage Systems
}

\author{
NEPOMUCENO, M. ${ }^{2}$, ALVES, P.L.C.A. ${ }^{3}$, DIAS, T.C.S. ${ }^{2}$ e PAVANI, M.C.M.D. ${ }^{3}$
}

\begin{abstract}
RESUMO - A presente pesquisa objetivou estudar os efeitos dos períodos de controle e de convivência de uma comunidade infestante sobre as características produtivas da soja nos sistemas de semeadura direta (SSD), com o cultivar CD 201, e convencional (SSC), com a M-SOY-6101. No SSD, a comunidade infestante foi composta principalmente por Alternanthera tenella, Cenchrus echinatus e Bidens pilosa, com densidade máxima de 377 plantas $\mathrm{m}^{-2}$, acumulando 365,7 $\mathrm{g} \mathrm{m}^{-2}$ de matéria seca, e, no SSC, por A. tenella, Senna obtusifolia e Panicum maximum, com densidade máxima de 161 plantas $\mathrm{m}^{-2}$, acumulando $406,7 \mathrm{~g} \mathrm{~m}^{-2}$. Tolerando cinco por cento de perda na produtividade da cultura, constatou-se que os períodos críticos de prevenção da interferência foram dos 33 aos 66 DAE para o cultivar CD 201 no SSD e dos 34 aos 76 DAE para o cultivar M-SOY-6101 no SSC. A interferência das plantas daninhas durante todo o ciclo da cultura reduziu, em média, $46 \%$ (SSD) e $32 \%$ (SSC) a produtividade de grãos da soja. Não houve efeito das plantas daninhas na estatura das plantas, na altura de inserção da primeira vagem e no número de vagens por planta.
\end{abstract}

Palavras-chave: competição, Glycine max, períodos de controle.

\begin{abstract}
This work aimed to determine the interference of weed communities in crop yield characteristics, under no-till and conventional till systems. The soybean cultivars used in these experiments were M-SOY - 6101 and CD 201 for conventional and no-till, respectively. The no-till system weed community reached its maximum value of 377 plants $m^{-2} 28$ days after soybean emergence. Maximum dry matter accumulation was $365.7 \mathrm{~g} \mathrm{~m}^{-2}, 118$ days after emergence, with the main plants being Alternanthera tenella, Cenchrus echinatus and Bidens pilosa. Under the conventional till system, maximum density was 161 plants $m^{-2}, 18$ DAE and $406.7 \mathrm{~g} \mathrm{~m}^{-2}$ of dry matter accumulation at $118 \mathrm{DAE}$, with the main plants being A. tenella, Senna obtusifolia and Panicum maximum. Accepting losses of 5\% in soybean productivity, the CPPI values were estimated to range from 33 to 66 DAE for the no-till system and from 34-76 DAE for the conventional till system. Weed interference during the full crop cycle reduced, in average, 46 and $32 \%$ of productivity under the no- till and conventional till systems, respectively. No effects were observed on plant height, first pod insertion height, and number of pods per plant due to the presence of weed community.
\end{abstract}

Keywords: competition, Glycine max, control periods.

\section{INTRODUÇÃO}

A cultura da soja constitui-se na mais importante oleaginosa cultivada no mundo. No âmbito mundial, o Brasil é o segundo maior produtor e um dos principais exportadores dos grãos. A soja está sujeita a uma série de fatores que podem influenciar o seu desenvolvimento e a produção. As plantas daninhas acarretam perdas na produtividade devido, principalmente, à competição por luz, nutrientes e água, além de dificultarem a colheita. Atuam também

Recebido para publicação em 18.9.2006 e na forma revisada em 27.2.2007.

2 Eng.-Agrônomo, Mestrando em Produção Vegetal, Universidade Estadual Paulista - FCAV/UNESP, Campus de Jaboticabal, <mariluce_n@hotmail.com>,<tesdias@fcav.unesp.br. ${ }^{3}$ Prof. Ass. Dr., Dep. de Biologia Aplicada à Agropecuária - FCAV/UNESP, Campus de Jaboticabal, 14884-900 Jaboticabal-SP, <plalves@fcav.unesp.br>, mcarmo@fcav.unesp.br>. 
como hospedeiras de pragas e doenças e exercem pressão de natureza alelopática. O grau de interferência causado pelas plantas daninhas na cultura depende da época e duração do período de convivência (Pitelli, 1985).

As determinações dos períodos de convivência tolerados por uma cultura com as plantas daninhas são obtidas estudando-se os períodos críticos de interferência (Pitelli \& Durigan, 1984). Diversos autores, no Brasil, têm determinado os períodos críticos de convivência e controle de plantas daninhas para culturas anuais, tendo-se observado que eles não ocorrem de forma similar. Isso é normal, porque as condições de desenvolvimento em que foram conduzidos os ensaios, bem como os próprios cultivares utilizados e as composições específicas das comunidades infestantes, são diferentes (Pitelli, 1980).

Com relação às condições de desenvolvimento, a presença de restos culturais sobre a superficie do solo, que caracteriza o sistema de semeadura direta (SSD), pode acarretar mudança da composição da comunidade de plantas daninhas, pois a cobertura morta, deixada pelos restos da cultura anterior por ocasião da colheita ou pela dessecação e/ou rolagem da cobertura vegetal, exerce forte influência física, química e biológica sobre a germinação das plantas daninhas (Buzatti, 1999). No tocante aos cultivares, sabe-se que, em decorrência principalmente do vigor e da arquitetura das plantas, eles também podem alterar a composição da comunidade infestante, pois existem alguns com elevada capacidade competitiva com as plantas daninhas. Lamego et al. (2004) evidenciaram que cultivares de soja com características dissimilares portadores de habilidade competitiva superior, além de tolerarem a competição, preservando o potencial de produtividade de grãos, também causaram supressão na produção de grãos das plantas concorrentes associadas. Pires et al. (2005), através de uma análise conjunta de várias características, constataram que, entre os cultivares de ciclo precoce, alguns mostraram ser mais competitivos com as plantas daninhas e são indicados para áreas de maior incidência destas plantas. Algumas pesquisas, para determinação do período anterior à interferência (PAI) e período total de prevenção da interferência das plantas daninhas (PTPI), foram realizadas por Durigan (1983), Spadotto et al. (1994), Carvalho \& Velini (2001) e Meschede et al. (2002).

A presente pesquisa objetivou estudar os efeitos dos períodos de controle e de convivência de uma comunidade infestante sobre a produção da soja, por meio da determinação do período anterior à interferência (PAI), período total de prevenção da interferência (PTPI) e período crítico de prevenção à interferência (PCPI), nos sistemas de semeadura direta (SSD) e convencional (SSC).

\section{MATERIAL E MÉTODOS}

Esta pesquisa constou de dois experimentos, ambos conduzidos na área experimental pertencente à Faculdade de Ciências Agrárias e Veterinárias da Universidade Estadual Paulista - UNESP, localizada no município de Jaboticabal - SP, na estação das águas (novembro a março). O solo foi classificado como Latossolo Vermelho eutrófico típico de textura argilosa. O clima da região de Jaboticabal, com base na classificação internacional de Köppen, é do tipo Cwa. Na época das águas predominam as chuvas de verão, com inverno relativamente seco. A temperatura média do mês mais quente é superior a $22^{\circ} \mathrm{C}$, e da do mês mais frio, inferior a $18{ }^{\circ} \mathrm{C}$, sendo a precipitação anual de $1.440 \mathrm{~mm}$.

Os cultivares de soja utilizados foram M-SOY-6101 e CD 201, para o SSC e SSD, respectivamente, ambos semeados no espaçamento de 0,45 m entre linhas, depositando-se 20 sementes por metro linear. Realizou-se a adubação no sulco de plantio com $300 \mathrm{~kg} \mathrm{ha}^{-1}$ da formulação 4-20-20. Em ambos os sistemas os tratamentos experimentais constaram de dois grupos: no primeiro, a cultura da soja permaneceu livre da convivência das plantas daninhas, através de capinas manuais, desde a emergência até $18,28,38,48,58,68$, 78 e 118 dias (todo o ciclo da cultura), que correspondeu ao grupo no mato (grupo M). No segundo grupo, no limpo (grupo L), a cultura ficou em convivência desde a emergência até os mesmos periodos descritos anteriormente, totalizando assim 16 tratamentos experimentais. O delineamento experimental foi em blocos casualizados, com quatro repetições. Ao 
término de cada período de convivência das plantas daninhas foi realizado levantamento da comunidade infestante, quando se determinou a densidade e a massa da matéria seca, ambas específicas e totais. Na colheita da cultura foi determinada a estatura de plantas, a altura de inserção da primeira vagem, o número de vagens por planta e a produtividade $\left(\mathrm{kg} \mathrm{ha}^{-1}\right)$, os quais foram submetidos à análise de variância pelo teste $F$, sendo as médias comparadas pelo teste de Tukey a $5 \%$ de probabilidade.

As análises dos dados de produtividade foram processadas separadamente, dentro de cada grupo (períodos iniciais de convivência ou de controle das plantas daninhas). Os resultados de produtividade foram submetidos à análise de regressão pelo modelo sigmoidal de Boltzman, conforme utilizado por Kuva et al. (2000). Esse modelo obedece à seguinte equação:

$$
Y=A_{2}+\left[\left(A_{1}-A_{2}\right) /(1+\exp (X-X o) / d x)\right]
$$

em que $Y$ é a produtividade estimada em grãos de soja, em $\mathrm{kg} \mathrm{ha}{ }^{-1} ; X$, o limite superior do período de convivência ou controle considerado; $A_{1}$, a produção máxima estimada obtida nas parcelas mantidas no limpo durante todo o ciclo da cultura; $A_{2}$, a produção mínima estimada decorrente das parcelas mantidas no mato durante todo o ciclo; Xo, o período superior do período de convivência ou controle, que corresponde ao valor intermediário entre a produção máxima e a mínima; e $d x$, o parâmetro que indica a velocidade de perda ou ganho de produção (tg $\alpha$ no ponto $X o$ ).

Com base nas equações de regressão, foram determinados os periodos de interferência das plantas daninhas para os niveis arbitrários de tolerância de 5\% de redução na produtividade dos grãos de soja, em relação ao tratamento mantido na ausência das plantas daninhas.

\section{RESULTADOS E DISCUSSÃO}

A comunidade infestante no SSD foi composta por 12 espécies de plantas daninhas, das quais $67 \%$ foram de dicotiledôneas e $33 \%$ de monocotiledôneas. Dentre elas, destacaramse visualmente três espécies: Alternanthera tenella (ALRTE), Bidens pilosa (BIDP) e Cenchrus echinatus (CCHEC).
No SSC, a comunidade infestante foi composta por 16 espécies de plantas daninhas, das quais $60 \%$ foram de dicotiledôneas e $40 \%$ de monocotiledôneas. Dentre as espécies que compuseram a comunidade infestante, três se destacaram visualmente: Alternanthera tenella (ALRTE), Senna obtusifolia (CASOB) e Panicum maximum (PANMA). As principais espécies de plantas daninhas monocotile dôneas que infestam a cultura da soja, especificamente no Estado de São Paulo, segundo Gelmini \& Diehl (1983) são: B. plantaginea, C. echinatus, $D$. sanguinalis, E. indica, Richardia roseum e Commelina virginica, e entre as dicotiledôneas: A. tenella, A. hispidum, A. australe, Amaranthus hybridus, Ageratum conyzoides, B. pilosa, Borreria alata, S. obtusifolia, Datura stramonium, Emilia sonchifolia, E. heterophylla, Euphorbia pilulifera, Galinsoga parviflora, Ipomoea purpurea, Nicandra physaloides, Portulaca oleracea, Polygonum convolvulus, Raphanus raphanistrum, Richardiabrasiliensis, Solanum americanum, Sida rhombifolia, S. glazioviie Sonchus oleraceus.

Analisando a densidade (Figura 1a) e o acúmulo de massa da matéria seca (Figura 2a) da comunidade infestante no SSD, em resposta aos periodos de convivência (grupo M), verificou-se que, aos 18 dias após a emergência (DAE) da cultura, as plantas daninhas atingiram densidade de 222 plantas $\mathrm{m}^{-2}$; aos $28 \mathrm{DAE}$, a densidade foi máxima (377 plantas $\mathrm{m}^{-2}$ ), devido à ocorrência de um segundo fluxo de emergência das plantas daninhas, decrescendo exponencialmente após e atingindo 56 plantas $\mathrm{m}^{-2}$ aos 118 DAE. A massa seca da parte aérea apresentou crescimento linear com o decorrer do tempo e foi máxima aos 118 DAE (colheita), atingindo $368 \mathrm{~g} \mathrm{~m}^{-2}$.

No SSC, a densidade da comunidade infestante (Figura 1b) decresceu exponencialmente com os aumentos dos periodos de convivência com a cultura. Aos $18 \mathrm{DAE}$, as plantas daninhas apresentaram a máxima densidade observada (161 plantas $\mathrm{m}^{-2}$ ), sendo reduzida para 29 plantas $\mathrm{m}^{-2}$ aos $118 \mathrm{DAE}$. Com relação à massa da matéria seca (MS) desta comunidade (Figura 2 b), verificou-se que o aumento foi exponencial, partindo de $2,5 \mathrm{~g} \mathrm{~m}^{-2}$ aos $18 \mathrm{DAE}$ e atingindo $406,7 \mathrm{~g} \mathrm{~m}^{-2}$ aos 118 DAE. 

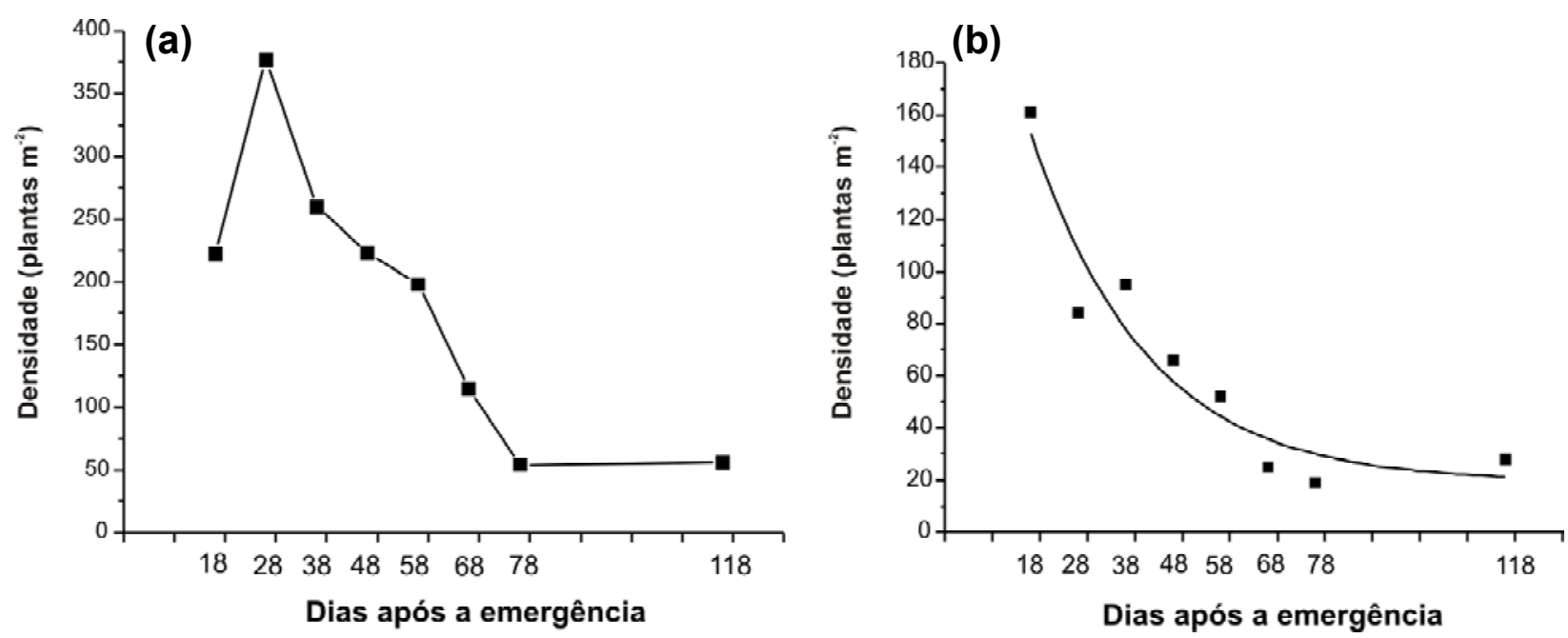

Figura 1 - Densidade das plantas daninhas em função do período de convivência no SSD (a) e SSC (b). UNESP, Jaboticabal, 2004.
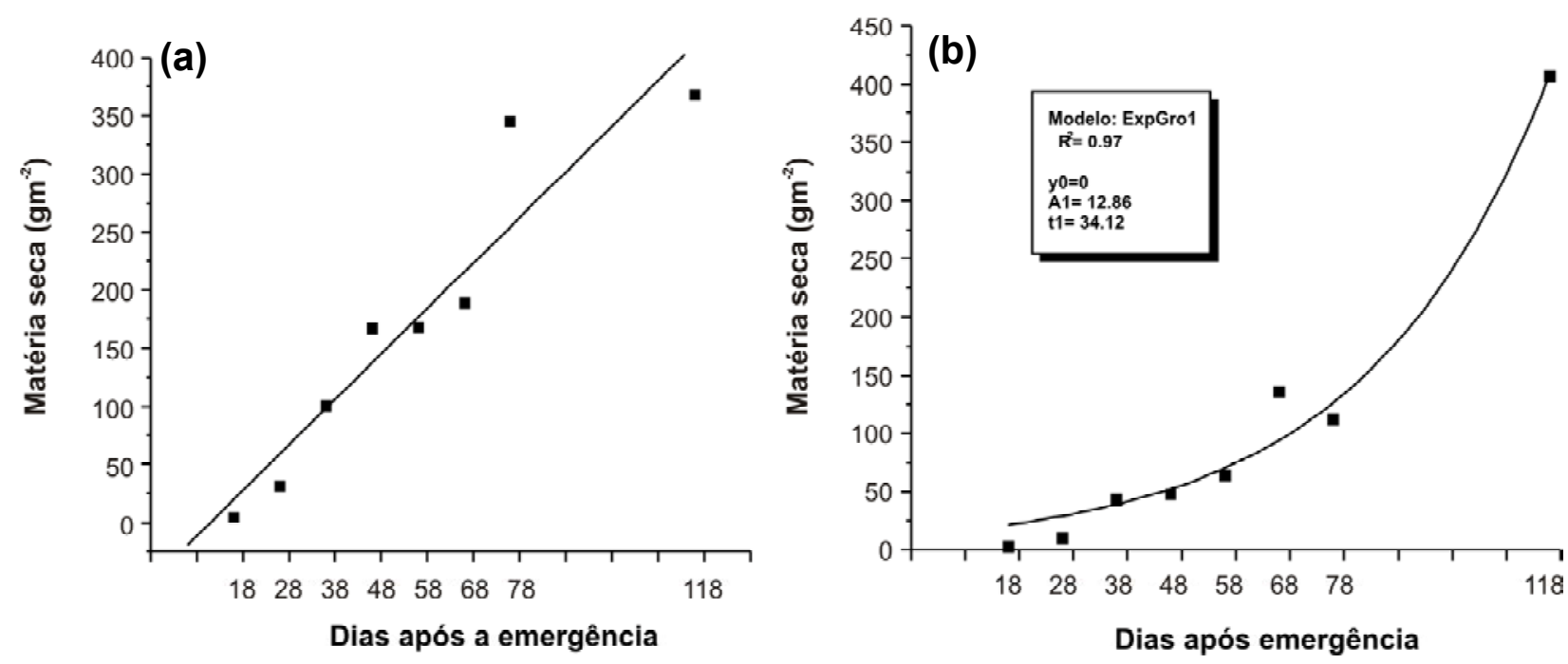

Figura 2 - Acúmulo de matéria seca das plantas daninhas em função do período de convivência no SSD (a) e SSC (b). UNESP, Jaboticabal, 2004.

De acordo com Radosevich \& Holt (1984), à medida que se aumenta a densidade e o desenvolvimento das plantas daninhas, especialmente daquelas que germinaram e emergiram no início do ciclo de uma cultura, como a da soja, intensifica-se a competição interespecífica e intra-específica, de modo que as plantas daninhas mais altas e desenvolvidas se tornam dominantes, ao passo que as menores são suprimidas ou morrem. Esse comportamento de uma comunidade infestante justifica a redução da densidade das plantas com o aumento da massa da matéria seca nos períodos de desenvolvimento finais da soja.
Embora os experimentos tenham sido instalados em uma mesma área, constatou-se diferenciação na composição da comunidade infestante, com menor diversidade de espécies no SSD, que se apresentaram em maior densidade e que praticamente acumularam o dobro da quantidade de matéria seca até 78 dias após a emergência da cultura, porém com biomassa se igualando à do SSC por ocasião da colheita. Resultados semelhantes, quanto à maior emergência de plantas daninhas, em maior nivel de palha foram encontrados por Correia et al. (2006), onde se esperava o contrário. No entanto, embora a palha possa 
influenciar negativamente a germinação de sementes, ela também pode favorecer algumas espécies de plantas daninhas, por meio da redução na amplitude de variação térmica diária do solo, da conservação da sua umidade ou, ainda, da melhoria física, química e biológica do solo.

Pelos resultados expressos na Tabela 1 , para o SSD, e na Tabela 2, para o SSC, verificou-se que em ambos os sistemas de semeadura não houve diferença significativa na estatura das plantas de soja, na altura de inserção da primeira vagem e no número de vagens por planta, em decorrência dos períodos de convivência ou controle das plantas daninhas.

Os resultados de produtividade de grãos de soja no SSD, no qual se utilizou o cultivar CD 201, podem ser analisados observando-se a Figura 3. Comparando a produtividade obtida na ausência total de plantas daninhas (testemunha no limpo) com a obtida na presença destas durante todo o ciclo (testemunha no mato), verificou-se redução de $46 \%$ na produtividade de grãos, sendo a produtividade máxima alcançada de $3.048 \mathrm{~kg} \mathrm{ha}^{-1}$.

Para o SSC, no qual se utilizou o cultivar M-SOY-6101, observa-se na Figura 4 que a redução imposta na produtividade de grãos pelas plantas daninhas que conviveram com a cultura durante todo o seu ciclo foi de $32 \%$, sendo a produtividade máxima de grãos de $3.338 \mathrm{~kg} \mathrm{ha}^{-1}$.

Nas Figuras 3 e 4 estão representadas as duas curvas ajustadas segundo Boltzman (Kuva et al., 2000): uma representando os rendimentos da produtividade em grãos de soja obtida nas plantas que permaneceram inicialmente em convivência com as plantas daninhas, ou seja, no mato (grupo M), que

Tabela 1 - Efeitos de períodos de convivência e de controle das plantas daninhas sobre a estatura de plantas, a altura de inserção da primeira vagem, o número de vagens por planta e a produtividade de grãos no sistema de semeadura direta (SSD). UNESP/Jabot icabal, 2004

\begin{tabular}{|c|c|c|c|c|c|}
\hline \multicolumn{2}{|c|}{ Tratamento } & Altura de plantas $(\mathrm{cm})$ & $\begin{array}{c}\text { Altura de inserção da } \\
1^{\mathrm{a}} \text { vagem }(\mathrm{cm})\end{array}$ & $\begin{array}{c}\mathrm{N}^{\mathrm{o}} \text { de vagens por } \\
\text { planta }^{1 /}\end{array}$ & $\begin{array}{l}\text { Produtividade de } \\
\text { grãos }\left(\mathrm{kg} \mathrm{ha}^{-1}\right)\end{array}$ \\
\hline 1 & No mato & 66,33 & 21,98 & 5,93 & $1.656 \mathrm{~B}$ \\
\hline 2 & $0-18 \mathrm{DL}^{\underline{L}}$ & 70,28 & 26,88 & 6,20 & $2.738 \mathrm{~A}$ \\
\hline 3 & $0-28 \mathrm{DL}$ & 70,63 & 24,48 & 6,42 & $2.710 \mathrm{AB}$ \\
\hline 4 & $0-38 \mathrm{DL}$ & 70,58 & 27,73 & 6,14 & $2.668 \mathrm{AB}$ \\
\hline 5 & $0-48 \mathrm{DL}$ & 69,85 & 26,63 & 6,38 & $2.820 \mathrm{~A}$ \\
\hline 6 & $0-58 \mathrm{DL}$ & 71,18 & 27,73 & 6,56 & $2.941 \mathrm{~A}$ \\
\hline 7 & $0-68 \mathrm{DL}$ & 67,95 & 26,63 & 6,54 & $2.723 \mathrm{AB}$ \\
\hline 8 & $0-78 \mathrm{DL}$ & 68,50 & 27,35 & 6,72 & $3.010 \mathrm{~A}$ \\
\hline 9 & $0-118 \mathrm{DL}$ & 67,90 & 27,78 & 6,45 & $3.048 \mathrm{~A}$ \\
\hline 10 & $0-18 \mathrm{DM}^{3 /}$ & 66,45 & 27,70 & 6,14 & $2.925 \mathrm{~A}$ \\
\hline 11 & $0-28 \mathrm{DM}$ & 65,07 & 27,73 & 6,37 & $2.916 \mathrm{~A}$ \\
\hline 12 & $0-38 \mathrm{DM}$ & 67,09 & 26,58 & 6,51 & $2.693 \mathrm{AB}$ \\
\hline 13 & $0-48 \mathrm{DM}$ & 65,65 & 22,50 & 6,42 & $2.693 \mathrm{~A}$ \\
\hline 14 & $0-58 \mathrm{DM}$ & 67,68 & 25,00 & 6,29 & $2.543 \mathrm{AB}$ \\
\hline 15 & $0-68 \mathrm{DM}$ & 65,20 & 23,60 & 5,97 & $2.364 \mathrm{AB}$ \\
\hline 16 & $0-78 \mathrm{DM}$ & 65,28 & 26,50 & 5,91 & $1.991 \mathrm{AB}$ \\
\hline \multicolumn{2}{|c|}{ F bloco } & $0,50 \mathrm{NS}$ & $2,11 \mathrm{NS}$ & $1,72 \mathrm{NS}$ & $4,08 *$ \\
\hline \multicolumn{2}{|c|}{$\mathrm{F}$ tratamento } & $0,73 \mathrm{NS}$ & $1,72 \mathrm{NS}$ & $1,57 \mathrm{NS}$ & $3,10 * *$ \\
\hline \multicolumn{2}{|c|}{ DMS } & 0,12 & 0,72 & 0,98 & 1.072 \\
\hline \multicolumn{2}{|c|}{$\mathrm{CV}(\%)$} & 7,12 & 11,91 & 6,09 & 15,96 \\
\hline
\end{tabular}

${ }^{1 /}$ Dados transformados para $\sqrt{x} ;{ }^{2 /} \mathrm{DL}=$ dias no limpo; ${ }^{3 /} \mathrm{DM}=$ dias no mato. Médias seguidas por mesma letra, na coluna, não diferem entre si pelo teste de Tukey a $5 \%$ de probabilidade. NS - não-significativo pelo teste $\mathrm{F}$. *** significativo estatisticamente a 5 e $1 \%$, respectivamente. 
Tabela 2 - Efeito de períodos de convivência e de controle das plantas daninhas sobre a estatura de plantas, a altura de inserção da primeira vagem, o número de vagens por planta e a produtividade de grãos no sistema de semeadura convencional (SSC). UNESP/Jaboticabal, 2004

\begin{tabular}{|c|c|c|c|c|c|}
\hline \multicolumn{2}{|c|}{ Tratamento } & Altura de plantas $(\mathrm{cm})$ & $\begin{array}{c}\text { Altura de inserção da } \\
1^{\mathfrak{a}} \text { vagem }(\mathrm{cm})\end{array}$ & $\begin{array}{c}\mathrm{N}^{\mathrm{o}} \text { de vagens por } \\
\text { planta }^{1 /}\end{array}$ & $\begin{array}{l}\text { Produtividade de } \\
\text { grãos }\left(\mathrm{kg} \mathrm{ha}^{-1}\right)\end{array}$ \\
\hline 1 & No mato & 110,28 & 24,40 & 5,87 & $2.266 \mathrm{C}$ \\
\hline 2 & $0-18 \mathrm{DL}^{2 /}$ & 117,23 & 24,83 & 5,87 & $2.621 \mathrm{BC}$ \\
\hline 3 & $0-28 \mathrm{DL}$ & 117,73 & 23,83 & 6,09 & $2.790 \mathrm{ABC}$ \\
\hline 4 & $0-38 \mathrm{DL}$ & 122,23 & 21,48 & 6,42 & $3.083 \mathrm{ABC}$ \\
\hline 5 & $0-48 \mathrm{DL}$ & 120,00 & 21,95 & 6,30 & $3.075 \mathrm{ABC}$ \\
\hline 6 & $0-58 \mathrm{DL}$ & 115,85 & 23,53 & 6,17 & $2.887 \mathrm{ABC}$ \\
\hline 7 & $0-68 \mathrm{DL}$ & 117,83 & 23,75 & 6,36 & $3.070 \mathrm{ABC}$ \\
\hline 8 & $0-78 \mathrm{DL}$ & 119,10 & 22,85 & 6,42 & $3.596 \mathrm{~A}$ \\
\hline 9 & $0-118 \mathrm{DL}$ & 119,10 & 25,00 & 6,45 & $3.338 \mathrm{AB}$ \\
\hline 10 & $0-18 \mathrm{DM}^{3 /}$ & 117,10 & 23,65 & 6,22 & $3.292 \mathrm{AB}$ \\
\hline 11 & $0-28 \mathrm{DM}$ & 115,83 & 25,30 & 6,12 & $3.118 \mathrm{ABC}$ \\
\hline 12 & $0-38 \mathrm{DM}$ & 116,78 & 25,53 & 5,92 & $2.631 \mathrm{ABC}$ \\
\hline 13 & $0-48 \mathrm{DM}$ & 116,65 & 25,20 & 5,95 & $3.118 \mathrm{ABC}$ \\
\hline 14 & $0-58 \mathrm{DM}$ & 111,05 & 24,95 & 5,62 & $2.631 \mathrm{BC}$ \\
\hline 15 & $0-68 \mathrm{DM}$ & 120,83 & 26,80 & 6,31 & $2.648 \mathrm{ABC}$ \\
\hline 16 & $0-78 \mathrm{DM}$ & 117,18 & 26,05 & 5,91 & $2.517 \mathrm{BC}$ \\
\hline \multicolumn{2}{|c|}{ F bloco } & $2,43 \mathrm{NS}$ & $1,06 \mathrm{NS}$ & $0,42 \mathrm{NS}$ & $3,41 *$ \\
\hline \multicolumn{2}{|c|}{ F tratamento } & $1,76 \mathrm{NS}$ & $1,92 \mathrm{NS}$ & $0,77 \mathrm{NS}$ & $3,74 * *$ \\
\hline \multicolumn{2}{|c|}{ DMS } & 0,12 & 0,57 & 1,59 & 879,92 \\
\hline \multicolumn{2}{|c|}{ CV $(\%)$} & 4,01 & 8,92 & 10,21 & 11,69 \\
\hline
\end{tabular}

${ }^{1 /}$ Dados transformados para $\sqrt{\mathrm{x}} ; \stackrel{2 /}{\mathrm{L}} \mathrm{DL}=$ dias no limpo; ${ }^{3 /} \mathrm{DM}=$ dias no mato. Médias seguidas por mesma letra, na coluna, não diferem entre si pelo teste de Tukey a $5 \%$ de probabilidade. NS - não-significativo pelo teste $\mathrm{F}$. * $* *$ significativo estatisticamente a 5 e $1 \%$, respectivamente.

permite a determinação do período anterior à interferência (PAI); e a outra representando os rendimentos das plantas que permaneceram inicialmente sem convivência com as plantas daninhas, ou seja, no limpo (grupo L), que permite a determinação do período total de prevenção da interferência (PTPI).

Tanto para o SSD como para o SSC foi realizada a estimativa dos valores do limite superior do PAI e do PTPI, considerando uma tolerância de redução de $5 \%$ na produtividade da cultura da soja. Tolerando-se essa redução, a produtividade da soja no SSD passou a ser afetada pela convivência com as plantas daninhas a partir de 33 dias após a emergência - DAE (PAI); o controle das plantas daninhas teve de ser realizado até os 66 DAE (PTPI), para que a produção da soja atingisse $95 \%$ da produção máxima (Figura 3). O intervalo entre esses dois períodos - ou seja, entre 33 e $66 \mathrm{DAE}$ - é caracterizado como período crítico de prevenção da interferência (PCPI). Para o SSC (Figura 4), o PAI encontrado foi de $34 \mathrm{DAE}$, e o PTPI, de 76 DAE; conseqüentemente, o PCPI foi dos 34 aos 76 dias após a emergência da soja. O PCPI corresponde ao período em que efetivamente a cultura deve ser mantida na ausência das plantas daninhas (Pitelli \& Durigan, 1984).

Considerando-se uma perda de $5 \%$ de produtividade, no sistema de semeadura direta, com predominância na comunidade infestante de Alternanthera tenella, Cenchrus echinatus e Bidens pilosa, o cultivar de soja CD 201 pode conviver com essa comunidade até 33 dias após sua emergência (PAI), com um período total de prevenção da interferência (PTPI) até $66 \mathrm{DAE}$, resultando em um período crítico de prevenção da interferência (PCPI) dos 33 aos 66 DAE. Neste sistema, as plantas daninhas reduziram em $46 \%$ a produção da soja. 


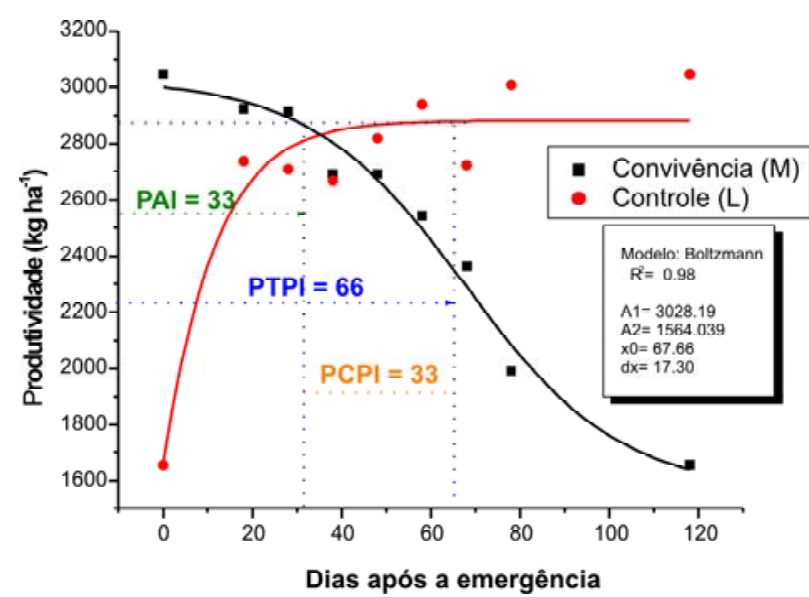

Figura 3 -Produtividade em grãos de soja, do cultivar CD 201, no SSD, em resposta aos períodos de controle e de convivência com as plantas daninhas, considerando uma perda de 5\% na produtividade. UNESP/Jaboticabal, 2004.

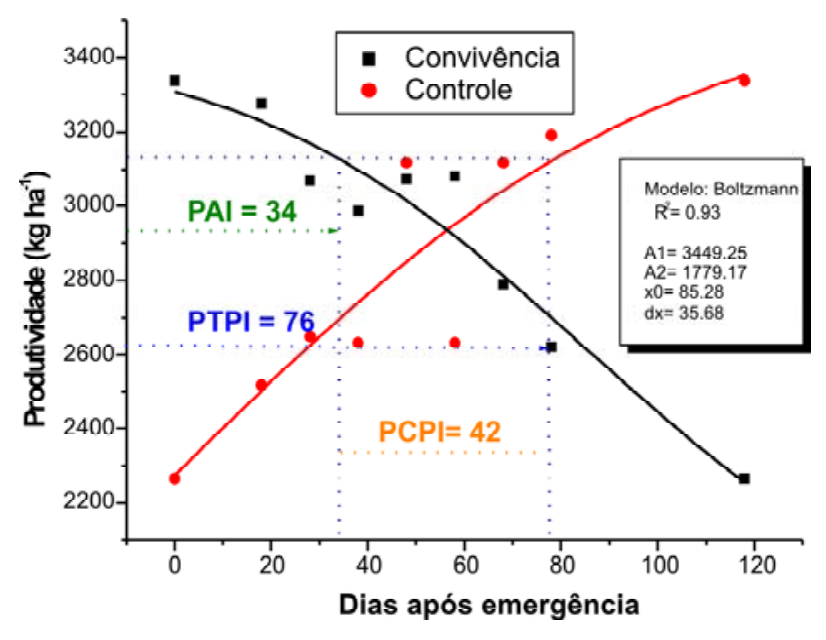

Figura 4 - Produtividade de grãos de soja, do cultivar M-SOY6101, no SSC, em resposta aos períodos de controle e de convivência com as plantas daninhas, considerando uma perda de 5\% na produtividade. UNESP/Jaboticabal, 2004.

No sistema de semeadura convencional, com predominância na comunidade infestante de Alternanthera tenella, Senna obtusifolia e Panicum maximum, o cultivar de soja M-SOY6101 pode conviver com essa comunidade até 34 dias após sua emergência (PAI), com PTPI de 76 DAE, resultando em PCPI dos 34 aos 76 DAE. Neste sistema, as plantas daninhas reduziram em $32 \%$ a produção da cultura da soja.
Embora os sistemas de manejo e os cultivares de soja tenham sido distintos, o periodo anterior à interferência (PAI) foi semelhante, em torno dos 30 dias após a emergência da cultura (DAE), com um período total de prevenção da interferência (PTPI) dez dias mais longo no SSC, estendendo-se até cerca dos $80 \mathrm{DAE}$, provavelmente em decorrência de menor densidade e acúmulo de matéria seca das plantas daninhas no periodo crítico de prevenção da interferência (PCPI). Como conseqüência, o cultivar CD 201 no SSD se mostrou mais sensivel à interferência das plantas daninhas, com maior redução em sua produtividade.

\section{LITERATURA CITADA}

BUZATTI, W. J. S. Controle de plantas daninhas no sistema plantio direto na palha. In: PAULETTI, V.; SEGANFREDO, R. Plantio direto: atualização tecnológica. São Paulo: Fundação Cargill/Fundação ABC, 1999. p. 97-111.

CARVAlHO, F. T.; VELINI, E. D. Períodos de interferência de plantas daninhas na cultura da soja. I - Cultivar IAC-11. Planta Daninha, v. 19, n. 3, p. 317-322, 2001.

CORREIA, N. M. et al. Influência do tipo e da quantidade de resíduos vegetais na emergência de plantas daninhas. Planta Daninha, v. 24, n. 2, p. 245-253, 2006.

DURIGAN, J.C. et al. Período de matocompetição na cultura da soja (Glycine max (L.) Merrill), cultivares Santa Rosa e IAC 2. 1 - Efeitos sobre os parâmetros de produção. Planta Daninha, v. 6, n. 2, p. 86-100, 1983.

GELMINI, G. A.; DIHEL, S. R. L. Controle das plantas daninhas na cultura da soja. Campinas: CATI, 1983. 23 p. (CATI. Boletim Técnico, 170).

KUVA, M. A. et al. Períodos de interferência das plantas daninhas na cultura da cana-de-açúcar. I Tiririca (Cyperus rotundus). Planta Daninha, v. 18, n. 2, p. 241-251, 2000.

LAMEGO, F. P. et al. Tolerância à interferência de plantas competidoras e habilidade de supressão por genótipos de soja - II. Resposta de variáveis de produtividade. Planta Daninha, v. 22, n. 4, p. 491-498, 2004.

MESCHEDE, D. K. et al. Período crítico de interferência de Euphorbia heterophylla na cultura da soja sob baixa densidade de semeadura. Planta Daninha, v. 20, n. 3, p. 381-387, 2002.

Planta Daninha, Viçosa-MG, v. 25, n. 1, p. 43-50, 2007 
PIRES, F. R. et al. Potencial competitivo de cultivares de soja em relação as plantas daninhas. Planta Daninha, v. 23, n. 4, p. 575-581, 2005.

PITELLI, R. A. Ervas daninhas x culturas anuais. A Granja, v. 36, n. 387, p. $56-61,1980$.

PITELLI, R. A.; DURIGAN, J. C. Terminologia para períodos de controle e de convivência das plantas daninhas em culturas anuais e bianuais. In: CONGRESSO BRASILEIRO DE HERBICIDAS E PLANTAS DANINHAS, 15., 1984, Belo Horizonte. Resumos... Belo Horizonte: SBHED, 1984. p. 37.
PITELLI, R. A. Interferência de plantas daninhas em culturas agrícolas. Inf. Agropec., v. 11, n. 129, p. 19-27, 1985.

RADOSEVICH, S. R.; HOLT, J. S. Weed ecology: implications for vegetation management. 2.ed. New York: John Wiley \& Sons, 1997. 263 p.

SPADOTTO, C. A. et al. Determinação do período crítico de prevenção da interferência de plantas daninhas na cultura de soja: uso do modelo "Broken-Stick". Planta Daninha, v. 12, n. 2, p. 59-62, 1994. 